\title{
Dexmedetomidine facilitates extubation in children who require intubation and respiratory support after airway foreign body retrieval: a case-cohort analysis of 57 cases
}

\author{
Xu Zhang ${ }^{1}$. $\cdot$ Jinhong $\mathrm{Wu}^{1} \cdot \mathrm{Lijun}_{\mathrm{Wang}}{ }^{1} \cdot$ Wenxian $\mathrm{Li}^{1}$
}

Received: 31 March 2018 / Accepted: 3 June 2018 / Published online: 9 June 2018

(c) Japanese Society of Anesthesiologists 2018

\begin{abstract}
Purpose This study aimed to investigate whether dexmedetomidine had sedative weaning advantage for extubation after airway foreign body (FB) removal in children.

Methods A retrospective case-cohort comparison study with total of 57 critical children who required mechanical ventilation after rigid bronchoscopy was performed. After tracheal intubation, group D (received dexmedetomidine $1 \mu \mathrm{g} / \mathrm{kg}$ over $10 \mathrm{~min}$, followed by an infusion of $0.8 \mu \mathrm{g} / \mathrm{kg} / \mathrm{h}$ ), and group RP (received remifentanil-propofol 6-10 $\mu \mathrm{g} / \mathrm{kg} / \mathrm{h}$ and $1-3 \mathrm{mg} /$ $\mathrm{kg} / \mathrm{h}$, respectively). The primary outcome was successful extubation rate on first weaning trial. The minor outcomes included weaning time, emergency agitation, coughing score and the incidence of respiratory adverse complications on emergency. Main results All 57 patients were included in the analysis, with 30 patients in group D and 27 controlled cases in group RP. The success rate of first weaning trial in the D group was 96.7 vs $77.8 \%$ in the RP group, risk ratio (RR) $1.56,95 \% \mathrm{CI}$ [0.78-1.98]. Time for resuming spontaneous breathing after termination infusion was shorter in the $\mathrm{D}$ group (median 8 min, IQR $15 \mathrm{~min}$ ) vs RP group (median $12 \mathrm{~min}$, IQR $19 \mathrm{~min}, P=0.02$, RR 0.56, 95\% CI 0.14-6.57).

Conclusions In mechanical ventilation of pediatric patients following rigid bronchoscopy, in comparison to remifentanilpropofol, dexmedetomidine is proved to have high success rate for weaning strategy.

What is already known? Remifentanil is proved to be effective for weaning in ICU patients. Dexmedetomedine can provide similar rates of smooth extubation for pediatric patients who underwent airway surgery.

What this article adds? Invasive ventilation is used for patients with severe comorbidity after airway surgery, but the correct strategy for pediatric extubation after removal of airway foreign body remains unclear. For these patients with short-term mechanical ventilation, dexmedetomedine may improve the extubation rate, when compared with remifentanil-propofol.
\end{abstract}

Keywords Foreign body $\cdot$ Extubation $\cdot$ Weaning

\section{Introduction}

Aspiration of foreign body is a common and critical emergency in preschool children [1]. The risk during emergency includes apnea and hypoxemia that requires tracheal intubation and mechanical ventilation in some life-threatening cases. Ensuring uneventful extubation without deteriorating outcomes is challenging for anesthetists and intensive care physicians. Outcomes following weaning failure vary

Wenxian Li

wenxianli66@gmail.com

1 Department of Anesthesiology, Eye \& ENT Hospital, Fudan University, 83 Fenyang Road, Shanghai 200031, China in critical patients, including hypoxemia, cardiac arrest and even death. In pediatric patients who need mechanical ventilation supportive therapy postoperatively, a mutually beneficial weaning strategy should be recommended for both.

Recent studies have shown that sedatives such as midazolam and propofol facilitate weaning from long-term ventilation $[2,3]$. Dexmedetomidine is a selective $\alpha_{2}$ adrenoceptor agonist with sedative, anxiolytic and analgesic effects, and is useful in facilitating extubation in patients with prolonged mechanical ventilation $[4,5]$. It also increases tolerance to surgical intervention of the airway, and is used in fiber-optic bronchoscopy, as well as in facilitating extubation in pediatric airway surgery [6]. However, there are very few reports from short-term ventilation, especially in pediatric patients with fundamental airway 
pathological change caused either by foreign body aspiration or iatrogenic injury.

The airway is extremely sensitive to stimulation after foreign body aspiration, and the underlying problem of hypoxemia exists even after foreign body removal due to pathological changes (preoperative airway compromise such as segmental atelectasis or pneumonia) and iatrogenic damages (hypercapnia due to manual jet ventilation) [7]. Several studies have evaluated the efficacy of remifentanil-propofol or sevoflurane to achieve successful extubation of patients from mechanical ventilation $[1,8]$. However, there is no standardized weaning protocol for pediatric patients who require intubation and respiratory support after airway foreign body removal.

The present study was performed to evaluate the weaning efficacy of dexmedetomidine in comparison with remifentanil-propofol in critical pediatric patients who needed mechanical ventilation post-operation. The primary outcome was successful rate of first weaning trial. The minor outcomes included time for extubation, vital parameters, weaning time, emergency agitation, coughing score and the incidence of respiratory adverse complications on emergency.

\section{Patients and methods}

\section{Eligibility criteria}

After obtaining approval from the Hospital Ethics Committee and written informed consent from patients, this retrospective, observational study was conducted between January 2011 and December 2015, in the anesthesiology department of the Eye and ENT Hospital of Fudan University (Shanghai, China), which is a tertiary-care university referral hospital. A total of 1255 cases of foreign body aspiration, aged 3-48 months, underwent rigid bronchoscopy. Exclusion criteria were: incomplete information, intubation or tracheotomy pre-operation, need for further invasive manipulation such as tracheotomy or thoracentesis, and emergency with non-invasive mechanical ventilation. All data were collected retrospectively based on patient charts.

In all cases, anesthesia was induced with $8 \%$ sevoflurane in oxygen $(6-8 \mathrm{l} / \mathrm{min})$, followed by intravenous fentanyl $(0.5 \mu \mathrm{g} / \mathrm{kg})$, propofol $(2-4 \mathrm{mg} / \mathrm{kg})$ and succinylcholine $(1 \mathrm{mg} / \mathrm{kg})$, and maintained with total intravenous anesthesia (TIVA) with remifentanil-propofol (12-20 $\mu \mathrm{g} / \mathrm{kg} / \mathrm{h}$ and 6-12 mg/kg/h, respectively). For topical anesthesia, $2 \%$ lidocaine (maximum dose $4 \mathrm{mg} / \mathrm{kg}$ ) was sprayed onto the epiglottis, larynx, and between the vocal cords. Manual jet ventilation (MJV, Manujet III, VBM, Germany) was used throughout the surgery. MJV was performed before insertion of the bronchoscopy by placing a special slim tube (inner diameter $=0.5 \mathrm{~mm}$ ) transnasally into the trachea. MJV guarantees a quick and efficient oxygenation during the procedure and has a high-pressure oxygen/air outlet, which is adjustable between 0.35 and $0.7 \mathrm{bar}(5-10 \mathrm{psi})$. The surgeons were all experts of pediatric airway surgery who had relevant experience for more than 5 years.

\section{Postoperative management}

After airway foreign body retrieval, laryngeal mask airway is the most commonly used supraglottic airway (SGA) for airway support, followed by mask and nasopharyngeal airway. If severe hypoxemia occurred, which was defined as an episode of progressive decrease of desaturation $<80 \%$ for $>60 \mathrm{~s}$, tracheal intubation was needed for ventilation support therapy after extraction of foreign body and rigid bronchoscopy. Prior to intubation, succinylcholine $(1 \mathrm{mg} / \mathrm{kg})$ and propofol $(2 \mathrm{mg} / \mathrm{kg})$ were bolused to facilitate tracheal intubation. The ventilator settings included: mode (pressure support ventilation, PSV), peak inspiratory pressure (PIP) $10 \mathrm{cmH}_{2} \mathrm{O}$, rate: $15-20 / \mathrm{min}$, positive end expiratory pressure (PEEP): $4 \mathrm{cmH}_{2} \mathrm{O}$ (or 5-6 cm if $\mathrm{FiO}_{2}>0.90$ ), inspiratory time: $0.3-0.5 \mathrm{~s}$, and $\mathrm{FiO}_{2}: 0.4-1.0$, depending on the clinical situation.

A total of 57 cases with short-term (within hours) supportive mechanical ventilation after airway foreign body retrieval were included in this study. Extubation was accomplished in post-anesthesia care unit (PACU) by anesthesiologists.

\section{Anesthetics for sedative choice}

The primary sedative choice for mechanical ventilation, either with dexmedetomidine $(n=30,0.8 \mu \mathrm{g} / \mathrm{kg}$ bolus over $10 \mathrm{~min}$ followed by an infusion of $0.4 \mu \mathrm{g} / \mathrm{kg} / \mathrm{h}$ ) or remifentanil-propofol $(n=27,0.05-0.2 \mu \mathrm{g} / \mathrm{kg} / \mathrm{min}$ and $4-6 \mathrm{mg} / \mathrm{kg} / \mathrm{h}$, respectively), was based on a longitudinal practice alter (remifentanil as the first choice prior to 2012, whereas after 2012, after added to our hospital formulary, most patient with airway compromise received dexmedetomidine to maintain spontaneous respiration.)

\section{Weaning trial}

The sedative infusion was terminated if the patient met the following criteria: $\mathrm{SPO}_{2}>90 \%$ (with $\mathrm{FiO}_{2}<0.50$ ), $\mathrm{ETCO}_{2}<55 \mathrm{mmHg}$, minimal secretions and stable cardiopulmonary status. Weaning trial of spontaneous breathing trials (SBTs) with low-level pressure support [9] was attempted. Extubation was performed if three of the following four conditions were met: (1) regular respiratory pattern (within 15-30 bpm); (2) effective protective airway reflex without persisting coughing; (3) eye open or facial grimace with face touching; (4) $\mathrm{SPO}_{2}>90 \%\left(\mathrm{FiO}_{2}<0.50\right)$. 
For patients suffered from the failed first weaning failure, an alternative infusion of dexmedetomidine $(1 \mu \mathrm{g} / \mathrm{kg}$ bolus over $10 \mathrm{~min}$ followed by an infusion of $0.8 \mu \mathrm{g} / \mathrm{kg} / \mathrm{h}$ ) was used for sustained mechanical ventilation.

The weaning time referred to the time from termination of dexmedetomidine (or remifentanil-propofol) infusion to the time that meet the criteria of extubation. Extubation time was defined as the time from termination of infusion to successful extubation. Extubation failure is defined as inability to tolerate removal of tracheal tube, usually with severe hypoxemia episode, with the rescue method of reintubation or supraglottic airway. Patients were kept in the PACU until the Aldrete score was $\geq 9$ [10].

\section{Observed demographic characteristics}

Data of each patient was obtained by two observers who were blinded to the patient grouping. The medical records included age, gender, weight, the type and location of foreign body, duration of foreign body retention, duration of the procedure, occurrence of adverse respiratory events, sedative choice, vital signs after extubation and outcome.

\section{Adverse outcomes}

Coughing score after extubation was defined as: Grade $0=$ no cough; Grade $1=$ occasional cough of mild severity; Grade $2=$ cough persistence $<5$ s of moderate severity; Grade $3=$ severe, persistent cough for $>5 \mathrm{~s}$ (bucking) [11]. In our study, persistent coughing was defined as coughing score $\geq 3$. Emergence delirium (ED) was defined using the Pediatric Anesthesia Emergence Delirium (PAED) score $\geq 12$ [12].

In our previous study, the incidence of successful extubation was $85 \%$ in pediatric patients with mechanical ventilation after foreign body retrieval.

\section{Statistical analysis}

All data were analyzed using SPSS 16.0 software (SPSS Inc, Chicago, IL, USA). Quantitative variables (with abnormal distribution) are presented as median (min-max) and analyzed by Student's $t$ test. Data with non-parametric distribution were compared using Mann-Whitney $U$ test. Qualitative data are expressed as frequencies and compared using Chisquared test or Fisher's exact test. Risk ratios are reported for success rate of weaning trial. Differences were considered significant when $p<0.05$.

\section{Results}

A total of 57 patients with therapeutic mechanical ventilation after rigid bronchoscopy were enrolled in the study (Fig. 1). The patient demographic data were compared between the two groups (Table 1). The median (IQR, [range]) age was 17 (15-36 [2-48]) months. There were no differences in age, weight, gender, type and retention time of foreign body, anesthesia and surgery time, and reason for mechanical ventilation post-operation between the two groups (Table 1). There were no significant differences in the end-tidal carbon dioxide $\left(\mathrm{ETCO}_{2}\right)$ concentration on initiation of intubation, time for $\mathrm{ETCO}_{2}$ to reach $<55 \mathrm{mmHg}$ and weaning time between the two groups. The mean blood pressure, heart rate and respiratory rate were lower at extubation in the RP group without significant difference, and also at 1 and 5 min after extubation. There were no significant differences in the incidence of persistent coughing and emergence agitation (shown in Table 2). As compared to the $\mathrm{D}$ group, time to resume spontaneous breathing was significantly longer (8 [5-42] min vs 12 [6-83] min) and first extubation failure was higher in the RP group (adjusted OR 3.2, 95\% CI 1.35-5.6, $p=0.002)$. There were six episodes during the weaning phase including: breath holding $(n=1)$, persistent coughing $(n=2)$ and laryngospasm $(n=2)$ in the RP group, and tracheorrhagia $(n=1)$ in the D group. Among the six patients with failed weaning trial and extubation, three patients accepted mask ventilation with an uneventful recovery, while the other three cases (50\%) required re-intubation within half hour after extubation, sedative agents were switched to dexmedetomidine-based mechanical

Fig. 1 Patient inclusion

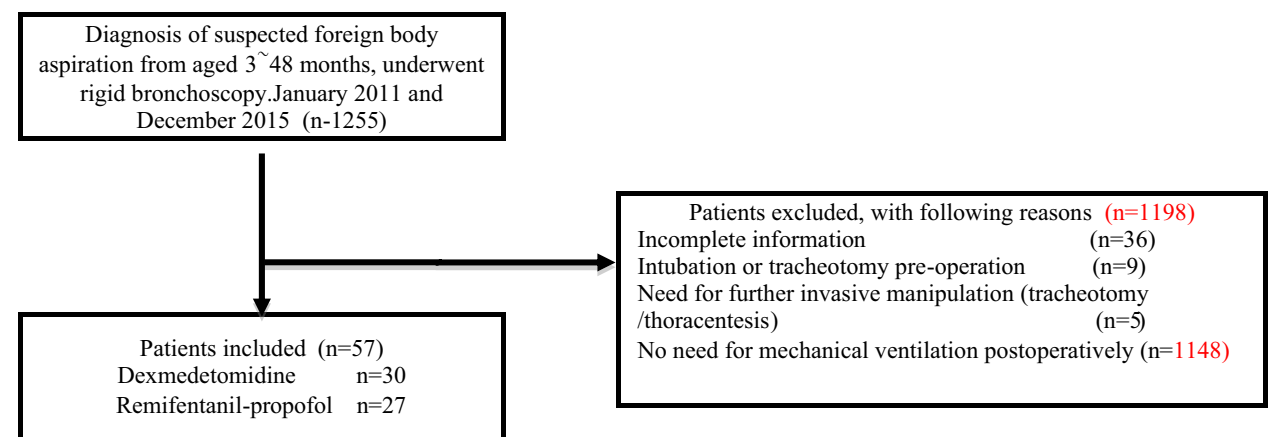


Table 1 Demographic and recovery data in the two study groups

\begin{tabular}{|c|c|c|c|}
\hline Characteristics & D Group $(n=30)$ & RP Group $(n=27)$ & $p$ \\
\hline Age [months] (range) & $15(7-48)$ & $16(9-46)$ & 0.74 \\
\hline $1-3$ months & 1 & 0 & \\
\hline $3-6$ months & 2 & 2 & \\
\hline $6-12$ months & 1 & 3 & \\
\hline $12-24$ months & 7 & 9 & \\
\hline 24-48 months & 4 & 2 & \\
\hline Weight $[\mathrm{kg}]$ (range) & $12(8.5-15)$ & $11(5.5-16)$ & 0.61 \\
\hline Gender (male/female) & $18 / 12$ & $14 / 13$ & 0.58 \\
\hline $\begin{array}{l}\text { Interval between removal and aspiration } \\
\text { episode [days] (range) }\end{array}$ & $19.5(1-64)$ & $21(1-90)$ & 0.81 \\
\hline \multicolumn{4}{|l|}{ Type of FB } \\
\hline Organic/inorganic & $21 / 7$ & $19 / 8$ & 0.36 \\
\hline Location of FB & & & 0.27 \\
\hline Right main bronchus $(n, \%)$ & $13(43.3)$ & $9(33.3)$ & \\
\hline Left main bronchus $(n, \%)$ & $11(36.7)$ & $10(37)$ & \\
\hline Main stem $(n, \%)$ & $4(13.3)$ & $5(18.5)$ & \\
\hline Subglottic region $(n, \%)$ & $2(6.7)$ & $3(11.1)$ & \\
\hline Duration of anesthesia [min] (range) & $27(13-76)$ & $22(11-70)$ & 0.95 \\
\hline Surgery time [min] (range) & $14(6-50)$ & $12(11-68)$ & 0.48 \\
\hline \multicolumn{4}{|l|}{ Reason for MV post-operation $(n, \%)$} \\
\hline Tracheorrhagia & $1(3.3)$ & $1(3.7)$ & 0.63 \\
\hline Segmental atelectasis & $3(10)$ & $2(7.4)$ & 0.51 \\
\hline Breath holding & $6(20)$ & $6(22.2)$ & 1.0 \\
\hline Laryngospasm/bronchospasm & $19(63.3)$ & $15(55.6)$ & 0.49 \\
\hline Pneumothorax & $1(3.3)$ & $2(7.4)$ & 1.0 \\
\hline Cardiac shock & $0(0)$ & $1(3.7)$ & 0.92 \\
\hline
\end{tabular}

Data are expressed as median (min-max) and the number (percentage) of patients

$F B$ foreign body, $M V$ mechanical ventilation ventilation, and successful extubation was achieved on the very next attempt.

\section{Discussion}

As compared to remifentanil-propofol, dexmedetomidine was more advantageous in facilitating extubation in children requiring mechanical ventilation after foreign body retrieval.

In patients with inhaled foreign body, a non-invasive ventilation (such as laryngeal mask airway) is usually used after the rigid bronchoscopy until spontaneous respiration is achieved. A minority of pediatric patients met the criteria for supportive mechanical ventilation, due to respiratory adverse events, such as hypoxemia (usually caused by consistent coughing), tracheorrhagia, segmental atelectasis (by $\mathrm{X}$-ray), pneumonia, pneumothorax and laryngospasm/bronchospasm. Prompt intubation and short-term mechanical ventilation lead to better oxygenation and outcome. In our previous study, the incidence of successful extubation was $85 \%$ in pediatric patients with mechanical ventilation after foreign body retrieval. The option of sedatives and anesthesia for ventilation support in patients remains an intractable issue for both anesthetists and intensive care physicians. Due to its superior characteristics in airway surgery, we hypothesize that dexmedetomidine can facilitate extubation and decrease adverse events.

Short-acting sedative is the major adjuvant drug for pressure support ventilation, with the improvement of ventilation-perfusion ratio $(V / Q)$.

Weaning failure is associated with worse outcome, and is usually caused by the following two conditions: persistent airway inflammation (leads to segmental emphysema, atelectasis and bronchospasm) [13] and hyperactive airway (caused by abundant secretions) [14, 15]. Ideal drugs for sedation could improve the pathophysiological changes, maintain adequate oxygenation, facilitate uneventful extubation and decrease the reintubation in emergency.

In our study, relative to the original 1255 cases enrolled data, only 57 cases finally met the conditions of entry into two groups who need mechanical ventilation, most cases were supported by mask or laryngeal mask airway without 
Table 2 Extubation-related events

\begin{tabular}{|c|c|c|c|c|}
\hline Characteristics & D Group $(n=30)$ & RP Group $(n=27)$ & $P$ value $[95 \% \mathrm{CI}]$ & $\operatorname{RR}[95 \% \mathrm{CI}]$ \\
\hline Emergence agitation $(n, \%)$ & $0(0)$ & $1(3.7)$ & $1.17[0.07-12.54]$ & $0.97[0.26-3.47]$ \\
\hline \multicolumn{5}{|c|}{$\mathrm{ETCO}_{2}$ while intubation $(\mathrm{mmHg})$} \\
\hline Mean & 61 & 58 & $0.09[0.32-6.43]$ & $1.14[0.89-4.32]$ \\
\hline Median & 57 & 53 & & \\
\hline IQR & 10 & 14 & & \\
\hline Range & $48-72$ & $43-69$ & & \\
\hline \multicolumn{5}{|l|}{$\mathrm{TCO}_{2}(\min )$} \\
\hline Mean & 55 & 65 & $0.06[0.01-3.21]$ & $0.65[0.25-2.69]$ \\
\hline Median & 52 & 63 & & \\
\hline IQR & 21 & 18 & & \\
\hline Range & $39-64$ & $28-96$ & & \\
\hline \multicolumn{5}{|l|}{ Ts (min) } \\
\hline Mean & $14^{*}$ & 18 & $0.02[0.00-3.45]$ & $0.56[0.14-6.57]$ \\
\hline Median & 8 & 12 & & \\
\hline IQR & 15 & 19 & & \\
\hline Range & $5-42$ & $6-83$ & & \\
\hline \multicolumn{5}{|l|}{ Weaning time (min) } \\
\hline Mean & 60 & 52 & $0.87[0.23-7.54]$ & $0.96[0.12-6.56]$ \\
\hline Median & 54 & 61 & & \\
\hline IQR & 31 & 38 & & \\
\hline Range & $21-95$ & $26-102$ & & \\
\hline \multicolumn{5}{|l|}{ Time to extubation ( $\mathrm{min}$ ) } \\
\hline Mean & 68 & 58 & $0.56[0.13-12.32]$ & $1.27[0.92-3.93]$ \\
\hline Median & 65 & 52 & & \\
\hline IQR & 15 & 27 & & \\
\hline Range & $39-82$ & $29-92$ & & \\
\hline \multicolumn{5}{|l|}{ Time to awake (min) } \\
\hline Mean & 104 & 89 & $0.07[0.13-12.32]$ & $1.62[0.56-10.5]$ \\
\hline Median & 98 & 65 & & \\
\hline IQR & 43 & 35 & & \\
\hline Range & $45-112$ & $46-108$ & & \\
\hline Weaning success $(n, \%)$ & $29(96.7)^{*}$ & $22(81.4)$ & 0.04 [0.07-11.67] & $1.09[0.06-5.32]$ \\
\hline Breath holding $(n, \%)$ & 0 & $1(3.7)$ & $0.12[0.01-9.42]$ & $0.98[0.23-3.46]$ \\
\hline Persistent coughing $(n, \%)$ & 0 & $2(7.4)$ & $0.12[0.07-12.54]$ & $0.98[0.23-3.46]$ \\
\hline Laryngospasm $(n, \%)$ & 0 & $2(7.4)$ & $0.12[0.07-12.54]$ & $0.98[0.26-3.46]$ \\
\hline Tracheorrhagia $(n, \%)$ & $1(100)$ & $0(0)$ & $0.32[0.02-9.63]$ & $1.01[0.02-4.32]$ \\
\hline Reintubation rate $(n, \%)$ & $0^{*}$ & $3(11.1)$ & $0.08[0.07-16.58]$ & $0.47[0.12-7.38]$ \\
\hline
\end{tabular}

Persistent coughing: coughing score $\geq 3$

Emergence agitation was defined as Pediatric Anesthesia Emergence Delirium score $\geq 12$

Data are expressed as number of patients (\%) (Chi-square test) $* p<0.05$

$\mathrm{T}_{\mathrm{CO} 2}$ time taken for $\mathrm{ETCO}_{2}$ to decrease to $<55 \mathrm{mmHg}$, Ts time taken to resume spontaneous breathing after termination of infusion further deteriorate oxygenation postoperatively. A failure of planned extubation usually includes post-extubation laryngeal edema [16] and weaker cough [17]. Severe hypoxemia caused by persistent coughing and apnea was the main reason for extubation failure.

This study confirmed the beneficial effect of dexmedetomidine for sedative patients who need postoperative mechanical ventilation. There were no differences in the fundamental complications between the two groups. The time for patients to resume spontaneous breathing and decrease of $\mathrm{ETCO}_{2}$ was quicker in the D group. In our study, dexmedetomidine (bolus $1 \mu \mathrm{g} / \mathrm{kg}$ followed by $0.8 \mu \mathrm{g} / \mathrm{kg} / \mathrm{h}$ ) did not significantly increase the weaning time as compared to remifentanil-propofol infusion. However, after termination 
of the infusion, the time to resumption of spontaneous respiration was significantly shorter.

Remifentanil is an ultra short-acting opioid analgesic. In combination with propofol, remifentanil could facilitate weaning from mechanical ventilation in pediatric intensive care [18]. In the current study, weaning failure in the first attempt was found in 6 out of 57 patients, due to breath holding, laryngospasm, persistent coughing and tracheorrhagia. In our study, three patients required reintubation following successful weaning trial in the remifentanil group, due to episodes of breath holding and laryngospasm. Remifentanil has well known analgesic and anesthetic properties. After remifentanil withdrawal, airway reflex and spontaneous respiration recovers rapidly [19] and pronociceptive system sensitization related hyperalgesia also resumes [20], combined with the development of agitation [21]. Aggressive airway reflex irritated by inflammation and secretion will cause persistent cough and laryngospasm, and deteriorate gas exchange leading to compromised airway.

The $\alpha_{2}$ agonist dexmedetomidine could attenuate airway-circulatory reflexes [22], maintain adequate sedation without hemodynamic instability or respiratory-drive depression [23-25], thereby attenuating hemodynamic stress secondary to hyperadrenergic over-reactivity [26]. It is also more effective than midazolam for sedation during prolonged mechanical ventilation [27]. As compared to mechanical ventilation, spontaneous respiration can attain better oxygenation and lower pulmonary shunt [28, 29]. Dexmedetomidine may help eliminate emergence agitation [30, 31], decrease the time from full to partial ventilatory support, and thereby facilitate earlier extubation [32].

In our study, 29 out of 30 patients in the dexmedetomidine group were successfully extubated without any weaning failure, only 1 patient suffered with tracheorrhagia followed by mask ventilation. We all use "no touch" technique [33] during emergence. As dexmedetomidine does not depress respiratory drive, the time to resume spontaneous breathing is significantly shorter in D group. Time to awake and extubate was longer in Group D than in Group RP, although there are no significant difference. Besides the sedative property of dexmedetomidine, it can also decrease secretion, led to less emergence agitation and upper airway reaction, and prolong the time of smooth emergency. While in remifentanil group, the hyperalgesia effect may play a major part in airway sensitivity, result in higher incidence of persistent coughing and breath holding, with the result of faster emergence. In pediatric patients with mechanical ventilation support following compromised airway, dexmedetomidine increased endotracheal tube tolerance, facilitated resumption of spontaneous respiration, and optimized ventilation and oxygen. During emergency, dexmedetomidine effectively suppresses cough [34] and agitation, facilitate successful extubation.
There were several limitations in our study. First, the small sample size of our patients exhibited various pathophysiological characteristics, from airway inflation to manipulation irritation, which could lead to patient bias. Second, the data were collected at different time periods with various strategies, which may lead to selection bias. We studied a relatively intensive patient population who needed mechanical ventilation after rigid bronchoscopy, and excluded children who needed sustained invasive manipulation, which may subject these children to unacceptable greater risks for postoperative respiratory complications. Hence, the results of our study may not be representative of the normal general population, and the beneficial effect of dexmedetomidine must be interpreted with caution. We plan to undertake more well-designed prospective clinical studies in the future to further confirm the advantages of dexmedetomidine in weaning.

In summary, dexmedetomidine sedation may be a more beneficial strategy, as compared to traditional analgesic and sedative combined regimens, in pediatric patients who need supportive ventilation after foreign body removal. Further studies would be needed to evaluate the usefulness of sedatives in such circumstances.

Funding This study was supported by the Social Development Research Project in Shanghai (ID: STCSM2014-14411969700).

\section{Compliance with ethical standards}

Ethical approval The institutional review board (EENT) waived the need for informed consent. Reference number: KY 2012-002.

Conflict of interest The authors declare that they have no conflict of Interest.

\section{References}

1. Paşaoğlu I, Doğan R, Demircin M, Hatipoğlu A, Bozer AY. Bronchoscopic extraction of foreign bodies in children: retrospective analysis of 822 cases. Thorac Cardiovasc Surg. 1991;39:95-8.

2. Saravanan P, Marnane C, Morris EA. Extubation of the surgically resected airway - a role for remifentanil and propofol infusions. Can J Anaesth. 2000;53(5):507-11.

3. Hoy SM, Keating GM. Dexmedetomidine: a review of its use for sedation in mechanically ventilated patients in an intensive care setting and for procedural sedation. Drugs. 2011;71(11):1481-01.

4. Hammer GB, Philip BM, Schroder AR, Rosen FS, Koltai PJ. Prolonged infusion of dexmedetomidine for sedation following tracheal resection. Pediatr Anesth. 2010;15(7):616-20.

5. Arpino PA, Kalafatas K, Thompson BT. Feasibility of Dex in facilitating extubation in the intensive care unit. J Clin Pharm Ther. 2008;33(1):25-30.

6. Silver AL, Yager P, Noviski N, Hartnick CJ. Dexmedetomidine use in pediatric airway reconstruction. Otolaryngol Head Neck Surg. 2011;144(2):262-7. 
7. Zaytoun GM, Rouadi PW, Baki DH. Endoscopic management of foreign bodies in the tracheobronchial tree: predictive factors for complications. Otolaryngol Head Neck Surg. 2000;123(3):311-6.

8. Goudra BG, Singh PM, Manjunath AK, Reihmer JW, Haas AR, Lanfranco AR, Sinha AC, Harris K. Effectiveness of high dose remifentanil in preventing coughing and laryngospasm in nonparalyzed patients for advanced bronchoscopic procedures. Ann Thorac Med. 2014;9(1):23-8.

9. Gupta S, Singh D, Sood D, Kathuria S. Role of dexmedetomidine in early extubation of the intensive care unit patients. J Anaesthesiol Clin Pharmacol. 2015;31(1):92-8.

10. Yang KL, Tobin MJ. A prospective study of indexes predicting the outcome of trials of weaning from mechanical ventilation. $\mathrm{N}$ Engl J Med. 1991;324(21):1445-50.

11. Aldrete JA. The post-operative recovery score revisited. J Clin Anesth. 1995;7:89-91.

12. Lee JH, Koo B-N, Jeong J-J, Kim H-S, Lee JR. Differential effects of lidocaine and remifentanil on response to the tracheal tube during emergence from general anaesthesia. Br J Anaesth. 2011;106:410-5.

13. Bajwa SA, Costi D, Cyna AM. A comparison of emergence delirium scales following general anesthesia in children. Paediatr Anaesth. 2010;20(8):704-11.

14. Fahy JV, Dickey BF. Airway mucus function and dysfunction. N Engl J Med. 2010;363:2233-7.

15. Saquib MM, Rauf KA, Al-Bassam A. Late presentation of tracheobronchial foreign body aspiration in children. J Trop Pediatr. 2005;511:145-8.

16. Salam A, Tilluckdharry L, Amoateng-Adjepong Y, Manthous CA. Neurologic status, cough, secretions and extubation outcomes. Intensive Care Med. 2004;30(7):1334-9.

17. François B, Bellissant E, Gissot V, Desachy A, Normand S, et al. 12-h pretreatment with methylprednisolone versus placebo for prevention of postextubation laryngeal oedema: a randomised double-blind trial. Lancet. 2007;369:1083-9.

18. Thille AW, Bossier F, Ben GH, Razazi K, Mekontsodessap A, Brunbuisson C. Risk factors for and prediction by caregivers of extubation failure in ICU patients: a prospective study. Crti Care Med. 2015;43(3):613-20.

19. Welzing L, Vierzig A, Junghaenel S, Eifinger F, Oberthuer A, Trieschmann U, Roth B. Remifentanil and propofol for weaning of mechanically ventilated pediatric intensive care patients. Eur J Pediatr. 2011;170(4):477-81.

20. Peacock JE, Luntley JB, O'Connor B, Reilly CS, Ogg TW, Watson BJ. Remifentanil in combination with propofol for spontaneous ventilation anaesthesia. Br J Anaesth. 1998;80(4):509-11.

21. Ryosuke I, Tetsuro N, Tatsuya H, Toshiko T, Yoji S. Intravenous infusion of remifentanil induces transient withdrawal hyperalgesia depending on administration duration in rats. Anesth Analg. 2012;114(1):224-9.

22. Crippen D. Agitation in the ICU: part one, anatomical and physiologic basis for the agitated state. Crit Care. 1999;3(3):R35-46.

23. Guler G, Akin A, Tosun Z, Eskitascoglu E, Mizrak A, Boyaci A. Acta single-dose dexmedetomidine attenuates airway and circulatory reflexes during extubation. Anaesthesiol Scand. 2005;49(8):1088-91.

24. Donaldson BP, Meyer-Witting M, Roux A. Awake fibreoptic intubation under remifentanil and propofol target-controlled infusion. Anaesth Intensive Care. 2002;30(1):93-5.

25. Venn RM, Hell J, Grounds RM. Respiratory effects of dexmedetomidine in the surgical patient requiring intensive care. Crit Care. 2000;4:302-8

26. Siobal MS, Kallet RH, Kivett VA, Tang JF. Use of dexmedetomidine to facilitate extubation in surgical intensive-careunit patients who failed previous weaning attempts following prolonged mechanical ventilation: a pilot study. Respir Care. 2006;51(5):492-6.

27. Jakob SM, Ruokonen E, Grounds RM, Sarapohja T, Garratt C, Pocock SJ, Bratty JR, Takala J. Dexmedetomidine vs midazolam or propofol for sedation during prolonged mechanical ventilation: two randomized controlled trials. JAMA. 2012;307(11):1151-60.

28. Putensen C, Mutz NJ, Putensen-Himmer G, Zinserling J. Spontaneous breathing during ventilatory support improves ventilationperfusion distributions in patients with acute respiratory distress syndrome. Am J Respir Crit Care Med. 1999;159(4):1241-8.

29. Le KN, Moffett BS, Ocampo EC, Zaki J, Mossad EB. Impact of dexmedetomidine on early extubation in pediatric cardiac surgical patients. Intensive Care Med. 2011;37(4):686-90.

30. Hall JE, Uhrich TD, Barney JA, Arain SR, Ebert TJ. Sedative, amnestic, and analgesic properties of small-dose dexmedetomidine infusions. Anesth Analg. 2000;90(3):699-05.

31. Kim SY, Kim JM, Lee JH, Song BM, Koo BN. Efficacy of intraoperative dexmedetomidine infusion on emergence agitation and quality of recovery after nasal surgery. Br J Anaesth. 2013;111(2):222-8.

32. Santak B, Radermacher P, Sandmann W, Falke KJ. Influence of SIMV plus inspiratory pressure support on A/distributions during postoperative weaning. Intensive Care Med. 1991;17:136-40.

33. Tsui BC, Wagner A, Cave D, Elliott C, El-Hakim H, Malherbe $\mathrm{S}$. The incidence of laryngospasm with a "no touch" extubation technique after tonsillectomy and adenoidectomy. Anesth Analg. 2004;98(2):327-9.

34. Lee JS, Choi SH, Kang YR, Kim Y, Shim YH. Efficacy of a single dose of dexmedetomidine for cough suppression during anesthetic emergence: a randomized controlled trial. Can J Anaesth. 2015;62(4):392-8. 